02

\title{
Кристаллическая структура и люминесценция комплекса $\left[\mathrm{Dy}\left(\mathrm{NO}_{3}\right)_{2}(\mathrm{HMPA})_{4}\right]\left(\mathrm{NO}_{3}\right)$
}

\author{
(C) Б.В. Буквецкий, А.Г. Мирочник , П.А. Жихарева \\ Институт химии Дальневосточного отделения РАН, \\ 690022 Владивосток, Россия \\ ฯe-mail: mirochnik@ich.dvo.ru
}

Поступила в редакцию 05.09.2018 г.

В окончательной редакции 05.11.18 г.

Принята к публикации 08.11.2018 г.

\begin{abstract}
Методом рентгеноструктурного анализа определена кристаллическая структура комплекса $\left[\mathrm{Dy}\left(\mathrm{NO}_{3}\right)_{2}(\mathrm{HMPA})_{4}\right]\left(\mathrm{NO}_{3}\right) \quad(\mathrm{HMPA}-$ гексаметилфосфотриамид). Кристаллы построены из двух кристаллографически независимых комплексных катионов $\left[\mathrm{Dy}\left(\mathrm{NO}_{3}\right)_{2}(\mathrm{HMPA})_{4}\right]^{+}$и внешнесферных $\left[\mathrm{NO}_{3}\right]^{-1}$-групп. Структура представлена изолированными комплексами $\mathrm{C}_{24} \mathrm{H}_{72} \mathrm{DyN}_{15} \mathrm{O}_{13} \mathrm{P}_{4}$, связанными ван-дер-ваальсовыми взаимодействиями с четко выраженным слоистым строением. Координационный полиэдр Dy(III) с координационным числом 8 представлен искаженной тригональной призмой с двумя центрированными квадратными гранями. Представлены результаты исследования люминесцентных свойств в видимом и ближнем ИК диапазонах.
\end{abstract}

DOI: $10.21883 /$ OS.2019.03.47366.268-18

Координационные соединения лантаноидов интересны своими уникальными люминесцентными и фотохимическими свойствами. Они могут быть использованы в качестве новых оптических материалов (светопреобразующие полимерные материалы, эффективные люминофоры в современных люминесцентных лампах, лазерные системы, индикаторные панели, органические светодиоды, рентгеновские экраны и др.) [1,2]. Фотофизические свойства комплексов на основе лантаноидов (узкие полосы излучения, большие стоксовы сдвиги и их длительный срок службы) делают их весьма перспективными для разработки высокочувствительных хемо- и триболюминесцентных сенсорных детекторов [3-5].

Координационные соединения Dy(III) (электронная конфигурация $4 f^{9}$ ) обладают интенсивной люминесценцией в видимом и ИК диапазонах, перспективны для развития люминофоров белого свечения [6-11] и оптических усилителей [12-14]. Следует отметить, что число публикаций, касающихся исследований ИК люминесценции комплексов Dy(III), весьма ограничено [14,15].

В продолжение наших работ по изучению взаимосвязи молекулярного строения и люминесцентных свойств комплексов состава $\left[\operatorname{Ln}\left(\mathrm{NO}_{3}\right)_{2}(\mathrm{HMPA})_{4}\right]\left(\mathrm{NO}_{3}\right)$ (НМРА - гексаметилфосфотриамид) [16-18] в настоящей работе нами исследован комплекс $\left[\mathrm{Dy}\left(\mathrm{NO}_{3}\right)_{2}(\mathrm{HMPA})_{4}\right]\left(\mathrm{NO}_{3}\right)$.

\section{Экспериментальная часть}

Комплексное соединение $\left[\mathrm{Dy}\left(\mathrm{NO}_{3}\right)_{2}(\mathrm{HMPA})_{4}\right]\left(\mathrm{NO}_{3}\right)$ синтезировано по следующей методике: $4 \mathrm{~g}$ кристаллогидрата нитрата диспрозия (Dy $\left.(\mathrm{NO})_{3} \cdot 6 \mathrm{H}_{2} \mathrm{O}\right)$ растворяли при $140-150^{\circ} \mathrm{C}$ в очищенном ГМФА (20-30 ml).
Соотношение исходных $\mathrm{Dy}(\mathrm{NO})_{3} \cdot 6 \mathrm{H}_{2} \mathrm{O}:$ ГМФА $\approx 1: 15$. После охлаждения раствора добавляли при энергичном перемешивании абсолютированный эфир (7 раз порциями по $40 \mathrm{ml}$ ) и сушили над $\mathrm{P}_{2} \mathrm{O}_{5}$. Выход продукта составил 92\%. Полученное соединение $\left[\mathrm{Dy}\left(\mathrm{NO}_{3}\right)_{2}(\mathrm{HMPA})_{4}\right]\left(\mathrm{NO}_{3}\right)$ представляет собой мелкокристаллический порошок желтого цвета, оно гигроскопично, хорошо растворимо в воде и спирте, нерастворимо в эфире и бензоле. Содержание $\mathrm{C}, \mathrm{H}, \mathrm{N}, \mathrm{O}, \mathrm{P}$ и Dy определяли методами элементного анализа. Процентное содержание углерода и водорода определяли сжиганием навески комплекса $\left[\mathrm{Dy}\left(\mathrm{NO}_{3}\right)_{2}(\mathrm{HMPA})_{4}\right]\left(\mathrm{NO}_{3}\right)$ в кварцевой трубке в токе кислорода в присутствии катализаторов. Содержание азота определяли методом Дюма сжиганием навески вещества в кварцевой трубке за счет кислорода твердых окислителей в атмосфере двуокиси углерода. Содержание Dу устанавливали весовым методом: прокаливали навеску вещества до постоянного веса окиси Р3Э.

Результаты элементного анализа комплекса $\left[\mathrm{Dy}\left(\mathrm{NO}_{3}\right)_{2}(\mathrm{HMPA})_{4}\right]\left(\mathrm{NO}_{3}\right)$ или $\mathrm{C}_{24} \mathrm{H}_{72} \mathrm{DyN}_{15} \mathrm{O}_{13} \mathrm{P}_{4}$ :

вычислено (\%): С, 27.06; Н, 6.81; N, 19.72; О, 19.52; Р, 11.63; Dy, 15.25;

найдено (\%): С, 27.0; Н, 6.79; N, 19.68; O, 19.38; Р, 11.59; Dy, 15.10 .

Рентгеноструктурное исследование проводили с помощью системы Карра APEXII CCD (MоK $K_{\alpha}$-излучение, графитовый монохроматор) с использованием программ [19]. Структура определялась прямым методом с использованием программ [20]. Положения атомов водорода рассчитывались и корректировались с помощью модели „наездника“. 


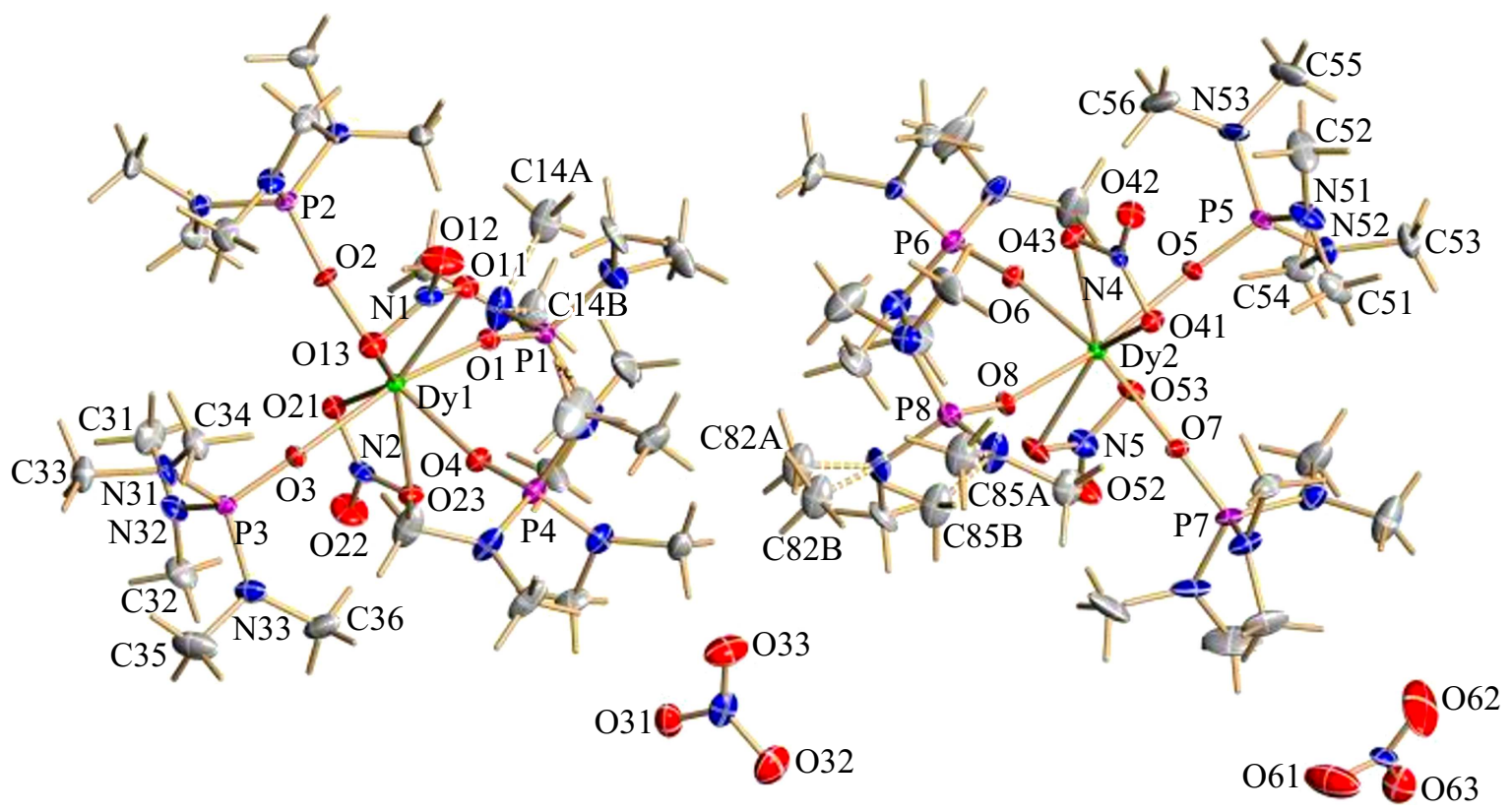

Рис. 1. Молекулярная структура комплекса $\left[\mathrm{Dy}\left(\mathrm{NO}_{3}\right)_{2}(\mathrm{HMPA})_{4}\right]\left(\mathrm{NO}_{3}\right)$.

CIF-файл, содержащий полную информацию об изучаемой структуре, депонирован в $\mathrm{CCDC}$ (Кембриджский центр кристаллографических данных) под номером 1560405 и может быть получен по запросу www.ccdc.cam.ac.uk/data_request/cif.

Основные кристаллографические параметры исследуемого образца, характеристики рентгеновского дифракционного эксперимента и детали уточнения модели структуры приведены в табл. 1, а основные межатомные расстояния и валентные углы - в табл. 2.

Спектры люминесценции и кинетика люминесценции регистрировались на спектрофлуориметре Horiba Fluorolog 3 (Япония). В качестве источника излучения использовалась ксеноновая лампа мощностью $450 \mathrm{~W}$. $\mathrm{B}$ качестве приемника излучения видимого диапазона использовался фотоэлектронный умножитель (диапазон $250-850 \mathrm{~nm}$ ), а в качестве приемника излучения ИК диапазона - InGaAs-детектор (диапазон 800-1500 nm), охлаждаемый жидким азотом. Регистрация спектров люминесценции видимого диапазона проводилась с шагом $1 \mathrm{~nm}$ при ширине спектральной щели $1 \mathrm{~nm}$ и времени усреднения $0.1 \mathrm{~s}$, а для ИК диапазона - с шагом $5 \mathrm{~nm}$ при ширине спектральной щели $14.7 \mathrm{~nm}$ и времени усреднения $2 \mathrm{~s}$. Квантовый выход люминесценции кристаллического образца измерен методом интегрирующей сферы.

\section{Результаты и обсуждение}

Молекулярная структура соединения $\left[\mathrm{Dy}\left(\mathrm{NO}_{3}\right)_{2}(\mathrm{HMPA})_{4}\right]\left(\mathrm{NO}_{3}\right)$ представлена на рис. 1.

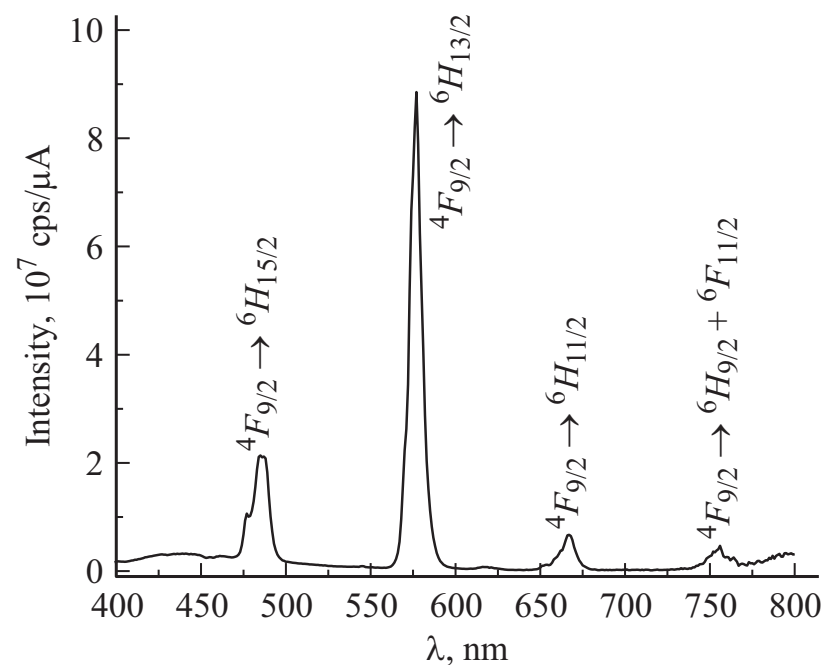

Рис. 2. Спектр люминесценции комплекса $\left[\mathrm{Dy}\left(\mathrm{NO}_{3}\right)_{2}(\mathrm{HMPA})_{4}\right]\left(\mathrm{NO}_{3}\right)\left(\lambda_{\mathrm{ex}}=324 \mathrm{~nm}\right)$.

Кристаллы $\left[\mathrm{Dy}\left(\mathrm{NO}_{3}\right)_{2}(\mathrm{HMPA})_{4}\right]\left(\mathrm{NO}_{3}\right)$ построены из двух кристаллографически независимых обособленных комплексных $\left[\mathrm{Dy}\left(\mathrm{NO}_{3}\right)_{2}(\mathrm{HMPA})_{4}\right]$-катионов и внешнесферных $\left[\mathrm{NO}_{3}\right]^{-1}$-групп. При координационном числе 8 четыре атома кислорода от четырех молекул гексаметилфосфотриамида и четыре атома кислорода от двух противолежащих $\mathrm{NO}_{3}$-групп образуют вокруг атома Dу искаженную двухшапочную тригональную призму с центрированными квадратными гранями (рис. 1). Ближайшие расстояния от люминесцентного центра Dy(III) до атомов водорода лигандов НМРА находятся в пре- 
Таблица 1. Кристаллографические данные, характеристики рентгендифракционного эксперимента и детали уточнения структуры $\left[\mathrm{Dy}\left(\mathrm{NO}_{3}\right)_{2}(\mathrm{HMPA})_{4}\right]\left(\mathrm{NO}_{3}\right)$

\begin{tabular}{|c|c|}
\hline Параметр & Значение \\
\hline Формула & $\mathrm{C}_{24} \mathrm{H}_{72} \mathrm{DyN}_{15} \mathrm{O}_{13} \mathrm{P}_{4}$ \\
\hline Молекулярная масса & 1065.35 \\
\hline Температура & $143(2) \mathrm{K}$ \\
\hline Длина волны & $\operatorname{MoK}_{\alpha}(0.71073 \AA)$ \\
\hline Пространственная группа & Pna $2_{1}$ \\
\hline$a, \AA$ & $16.9014(4)$ \\
\hline$b, \AA$ & $24.2447(5)$ \\
\hline$c, \AA$ & $23.4357(5)$ \\
\hline Z & 8 \\
\hline$\rho_{\text {Выч }}, \mathrm{g} / \mathrm{cm}^{3}$ & 1.474 \\
\hline$\mu, \mathrm{mm}^{-1}$ & 1.756 \\
\hline$F(000)$ & 4408 \\
\hline Размер кристалла, $\mathrm{mm}^{3}$ & $0.30 \times 0.25 \times 0.04$ \\
\hline Область сбора данных по $\theta$ & $1.47-27.51^{\circ}$ \\
\hline $\begin{array}{l}\text { Интервалы индексов } \\
\text { отражений }\end{array}$ & $\begin{array}{l}-21 \leq h \leq 21 \\
-31 \leq k \leq 31 \\
-30 \leq l \leq 30\end{array}$ \\
\hline Измерено отражений & 140651 \\
\hline Независимых отражений & $21969\left(R_{\text {int }}=0.0288\right)$ \\
\hline Отражений с $I>2 \sigma(I)$ & 17511 \\
\hline Комплексность по $\theta$ до $30.04^{\circ}$ & $100.0 \%$ \\
\hline Поглощение & $\begin{array}{c}\text { По индексам огранки } \\
\text { кристалла }\end{array}$ \\
\hline Метод уточнения & Полноматричный МНК по $F^{2}$ \\
\hline Переменных уточнения & 1076 \\
\hline$S$ & 1.043 \\
\hline$R$-факторы по $I>2 \sigma(I)$ & $R 1=0.0431, w R 2=0.0976$ \\
\hline $\begin{array}{l}R \text {-факторы по всем } \\
\text { отражениям }\end{array}$ & $R 1=0.0644, w R 2=0.1084$ \\
\hline $\begin{array}{l}\text { Абсолютный структурный } \\
\text { параметр }\end{array}$ & $0.507(7)$ \\
\hline $\begin{array}{l}\text { Остаточная эл. пл. } \\
(\min / \max ), e / \mathrm{A} 3\end{array}$ & $-0.756 / 0.859$ \\
\hline
\end{tabular}

делах $3.46-3.68 \AA$ для Dy1 и $3.46-3.61 \AA$ для Dy2 соответственно (рис. 1).

На рис. 2 и 3 показаны спектры люминесценции и возбуждения люминесценции комплекса $\left[\mathrm{Dy}\left(\mathrm{NO}_{3}\right)_{2}(\mathrm{HMPA})_{4}\right]\left(\mathrm{NO}_{3}\right)$ соответственно.

Исследуемый комплекс $\left[\mathrm{Dy}\left(\mathrm{NO}_{3}\right)_{2}(\mathrm{HMPA})_{4}\right]\left(\mathrm{NO}_{3}\right)$ обладает интенсивной люминесценцией: полосы на длинах волн $485,577,667$ и $756 \mathrm{~nm}$ (рис. 2), что соответствует электронным переходам $\mathrm{Dy}^{3+}{ }^{4} F_{9 / 2} \rightarrow{ }^{6} H_{J} \quad(J=15 / 2$, $13 / 2,11 / 2)$ и ${ }^{4} F_{9 / 2} \rightarrow{ }^{6} H_{9 / 2}+{ }^{6} F_{11 / 2}$ соответственно.

По данным анализа спектра возбуждения люминесценции комплекса (рис. 3), свечение обусловлено $f-f$-переходами $\mathrm{Dy}^{3+}$ (переходы ${ }^{6} P_{J} \leftarrow{ }^{4} H_{15 / 2}$ с $J=3 / 2,7 / 2$ (324 и $350 \mathrm{~nm}),{ }^{4} M_{15 / 2} \leftarrow{ }^{4} H_{15 / 2}(364 \mathrm{~nm})$, ${ }^{4} H_{13 / 2} \leftarrow{ }^{4} H_{15 / 2} \quad(388 \mathrm{~nm}),{ }^{4} G_{11 / 2} \leftarrow{ }^{4} H_{15 / 2} \quad(425 \mathrm{~nm})$, ${ }^{4} I_{15 / 2} \leftarrow{ }^{4} H_{15 / 2}(452 \mathrm{~nm})$ и и ${ }^{4} F_{9 / 2} \leftarrow{ }^{4} H_{15 / 2}(473 \mathrm{~nm})$.

Особенностью исследуемого комплекса является отсутствие внутримолекулярного переноса энергии элек-
Таблица 2. Основные длины связей и валентные углы в молекулах 1 и 2 в структуре $\left[\mathrm{Dy}\left(\mathrm{NO}_{3}\right)_{2}(\mathrm{HMPA})_{4}\right]\left(\mathrm{NO}_{3}\right)$

\begin{tabular}{|c|c|c|c|}
\hline Связь & $d, \AA$ & Угол & $\varphi$, deg \\
\hline 1 & 2 & 3 & 4 \\
\hline $\operatorname{Dy}(1)-O(2)$ & $2.235(3)$ & $\mathrm{O}(4)-\mathrm{Dy}(1)-\mathrm{O}(23)$ & $75.63(12)$ \\
\hline $\mathrm{Dy}(1)-\mathrm{O}(4)$ & $2.250(3)$ & $\mathrm{O}(3)-\mathrm{Dy}(1)-\mathrm{O}(23)$ & $78.91(12)$ \\
\hline $\operatorname{Dy}(1)-O(3)$ & $2.254(3)$ & $\mathrm{O}(1)-\mathrm{Dy}(1)-\mathrm{O}(23)$ & $79.30(12)$ \\
\hline $\operatorname{Dy}(1)-O(1)$ & $2.279(4)$ & $\mathrm{O}(2)-\mathrm{Dy}(1)-\mathrm{O}(11)$ & $78.50(12)$ \\
\hline $\operatorname{Dy}(1)-O(23)$ & $2.460(3)$ & $\mathrm{O}(4)-\mathrm{Dy}(1)-\mathrm{O}(11)$ & $79.74(12)$ \\
\hline $\mathrm{Dy}(1)-\mathrm{O}(11)$ & $2.463(3)$ & $\mathrm{O}(1)-\mathrm{Dy}(1)-\mathrm{O}(11)$ & $76.24(12)$ \\
\hline Dy $(1)-O(13)$ & $2.478(3)$ & $\mathrm{O}(2)-\mathrm{Dy}(1)-\mathrm{O}(13)$ & $81.14(12)$ \\
\hline $\mathrm{Dy}(1)-\mathrm{O}(21)$ & $2.479(3)$ & $\mathrm{O}(4)-\mathrm{Dy}(1)-\mathrm{O}(13)$ & $78.39(12)$ \\
\hline $\operatorname{Dy}(2)-O(6)$ & $2.241(3)$ & $\mathrm{O}(3)-\mathrm{Dy}(1)-\mathrm{O}(13)$ & $75.70(12)$ \\
\hline $\mathrm{Dy}(2)-\mathrm{O}(5)$ & $2.244(3)$ & $\mathrm{O}(11)-\mathrm{Dy}(1)-\mathrm{O}(13)$ & $51.86(12)$ \\
\hline $\mathrm{Dy}(2)-\mathrm{O}(7)$ & $2.246(3)$ & $\mathrm{O}(2)-\mathrm{Dy}(1)-\mathrm{O}(21)$ & $76.10(12)$ \\
\hline $\mathrm{Dy}(2)-\mathrm{O}(8)$ & $2.264(3)$ & $\mathrm{O}(3)-\mathrm{Dy}(1)-\mathrm{O}(21)$ & $79.97(12)$ \\
\hline $\mathrm{Dy}(2)-\mathrm{O}(43)$ & $2.465(3)$ & $\mathrm{O}(1)-\mathrm{Dy}(1)-\mathrm{O}(21)$ & $79.05(12)$ \\
\hline $\mathrm{Dy}(2)-\mathrm{O}(41)$ & $2.469(3)$ & $\mathrm{O}(23)-\mathrm{Dy}(1)-\mathrm{O}(21)$ & $51.80(10)$ \\
\hline $\mathrm{Dy}(2)-\mathrm{O}(53)$ & $2.474(3)$ & $\mathrm{O}(6)-\mathrm{Dy}(2)-\mathrm{O}(43)$ & $74.19(12)$ \\
\hline \multirow[t]{13}{*}{$\mathrm{Dy}(2)-\mathrm{O}(51)$} & $2.492(3)$ & $\mathrm{O}(5)-\mathrm{Dy}(2)-\mathrm{O}(43)$ & $79.31(12)$ \\
\hline & & $\mathrm{O}(8)-\mathrm{Dy}(2)-\mathrm{O}(43)$ & $82.20(12)$ \\
\hline & & $\mathrm{O}(5)-\mathrm{Dy}(2)-\mathrm{O}(41)$ & $81.62(12)$ \\
\hline & & $\mathrm{O}(7)-\mathrm{Dy}(2)-\mathrm{O}(41)$ & $75.00(12)$ \\
\hline & & $\mathrm{O}(8)-\mathrm{Dy}(2)-\mathrm{O}(41)$ & $80.39(12)$ \\
\hline & & $\mathrm{O}(43)-\mathrm{Dy}(2)-\mathrm{O}(41)$ & $51.65(11)$ \\
\hline & & $\mathrm{O}(6)-\mathrm{Dy}(2)-\mathrm{O}(53)$ & $81.68(12)$ \\
\hline & & $\mathrm{O}(5)-\mathrm{Dy}(2)-\mathrm{O}(53)$ & $74.30(12)$ \\
\hline & & $\mathrm{O}(7)-\mathrm{Dy}(2)-\mathrm{O}(53)$ & $79.70(12)$ \\
\hline & & $\mathrm{O}(6)-\mathrm{Dy}(2)-\mathrm{O}(51)$ & $80.35(12)$ \\
\hline & & $\mathrm{O}(7)-\mathrm{Dy}(2)-\mathrm{O}(51)$ & $80.79(13)$ \\
\hline & & $\mathrm{O}(8)-\mathrm{Dy}(2)-\mathrm{O}(51)$ & $74.54(12)$ \\
\hline & & $\mathrm{O}(53)-\mathrm{Dy}(2)-\mathrm{O}(51)$ & $51.51(11)$ \\
\hline
\end{tabular}

тронного возбуждения от уровней лигандов $\left(\mathrm{NO}_{3}\right.$, HМРA) на резонансные уровни люминесцентного центра, что обусловлено поглощением лигандов в коротковолновой УФ области. Значение квантового выхода люминесценции кристаллического образца, измеренное методом интегрирующей сферы, составляет $0.5 \%$.

Спектр ИК люминесценции (рис. 4) состоит из нескольких полос при $\lambda=966,1000,1146,1323$ и $1500 \mathrm{~nm}$, которые относятся к $f-f$-переходам ${ }^{4} F_{9 / 2} \rightarrow{ }^{6} H_{5 / 2},{ }^{6} F_{7 / 2},{ }^{6} F_{5 / 2},{ }^{6} F_{3 / 2}$ и ${ }^{6} F_{1 / 2}$ соответственно.

Кинетику люминесценции $\mathrm{Dy}^{3+}\left({ }^{4} F_{9 / 2}\right.$-уровень $)$ комплекса $\left[\mathrm{Dy}\left(\mathrm{NO}_{3}\right)_{2}(\mathrm{HMPA})_{4}\right]\left(\mathrm{NO}_{3}\right)$ измеряли при комнатной температуре с использованием длины волны возбуждения $320 \mathrm{~nm}$ (рис. 5).

Кинетика люминесценции описывается моноэкспоненциальной функцией, что согласуется с наличием в комплексе одного люминесцентного центра. Соответствующее время жизни возбужденного состояния Dу $\left({ }^{4} F_{9 / 2}\right)$ для комплекса $\left[\mathrm{Dy}\left(\mathrm{NO}_{3}\right)_{2}(\mathrm{HMPA})_{4}\right]\left(\mathrm{NO}_{3}\right)$ составляет $83 \pm 2 \mu \mathrm{s}$.

Методом рентгеноструктурного анализа определена кристаллическая структура комплекса 


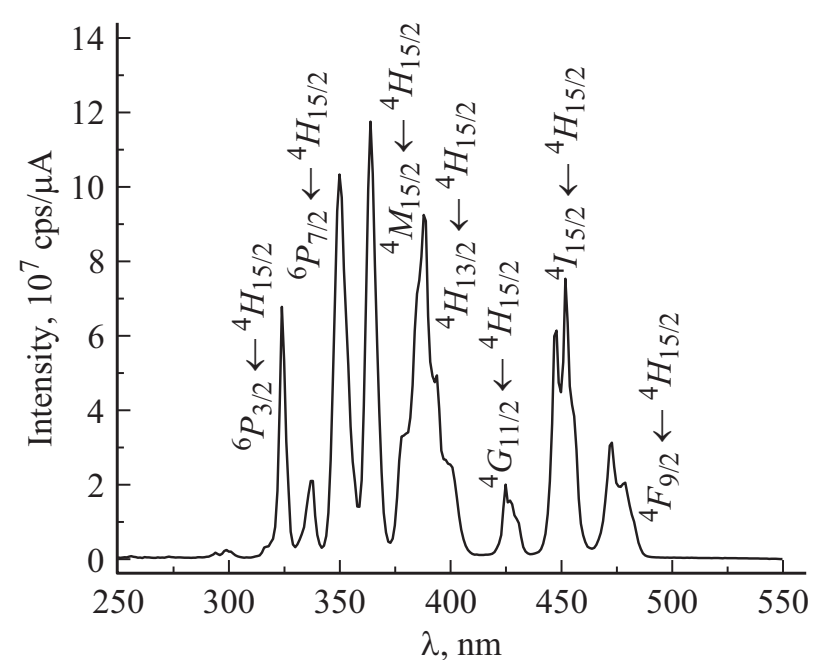

Рис. 3. Спектр возбуждения люминесценции комплекса $\left[\mathrm{Dy}\left(\mathrm{NO}_{3}\right)_{2}(\mathrm{HMPA})_{4}\right]\left(\mathrm{NO}_{3}\right)\left(\lambda_{\mathrm{reg}}=576 \mathrm{~nm}\right)$.

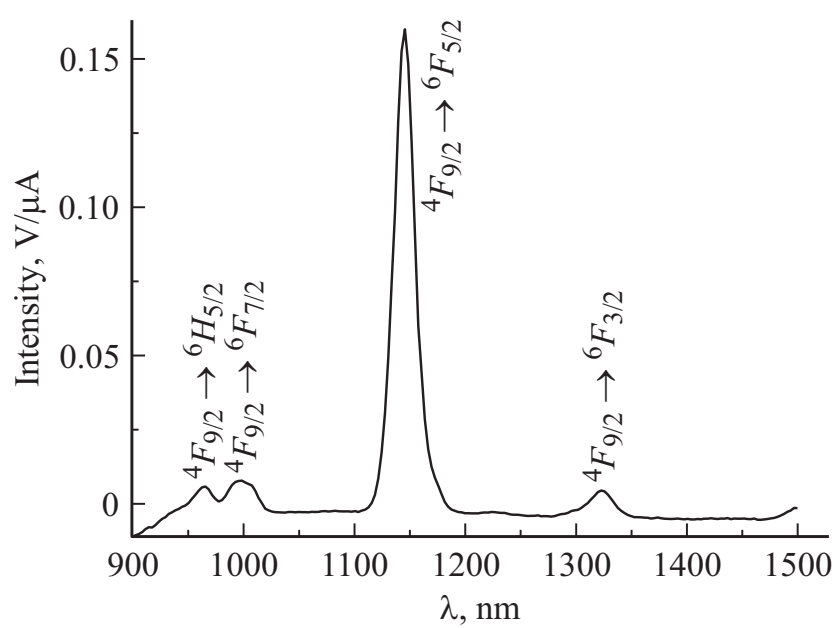

Рис. 4. Спектр ИК люминесценции $\left[\mathrm{Dy}\left(\mathrm{NO}_{3}\right)_{2}(\mathrm{HMPA})_{4}\right]\left(\mathrm{NO}_{3}\right)$ при $298 \mathrm{~K}\left(\lambda_{\mathrm{ex}}=324 \mathrm{~nm}\right)$.

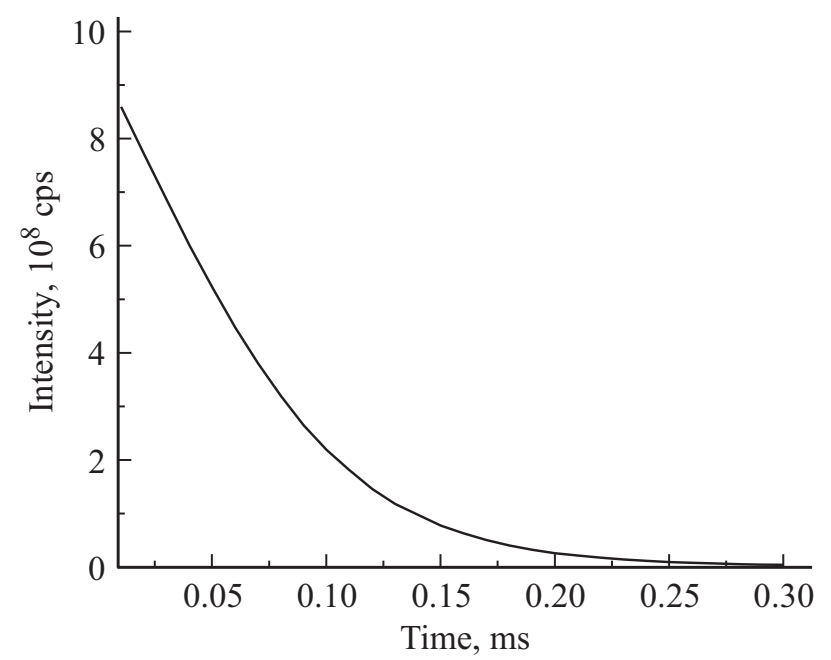

Рис. 5. Кинетика люминесценции $\left[\mathrm{Dy}\left(\mathrm{NO}_{3}\right)_{2}(\mathrm{HMPA})_{4}\right]\left(\mathrm{NO}_{3}\right)$ при $298 \mathrm{~K}\left(\lambda_{\mathrm{ex}}=324 \mathrm{~nm} ; \lambda_{\text {reg }}=576 \mathrm{~nm}\right)$.
$\left[\mathrm{Dy}\left(\mathrm{NO}_{3}\right)_{2}(\mathrm{HMPA})_{4}\right]\left(\mathrm{NO}_{3}\right) . \quad$ Структура представлена изолированными комплексами $\mathrm{C}_{24} \mathrm{H}_{72} \mathrm{DyN}_{15} \mathrm{O}_{13} \mathrm{P}_{4}$, связанными ван-дер-ваальсовыми взаимодействиями с четко выраженным слоистым строением. Координационный полиэдр Dy(III) с координационным числом 8 представлен искаженной тригональной призмой с двумя центрированными квадратными гранями. Представлены результаты исследования люминесцентных свойств в видимом и ближнем ИК диапазонах. Анализ спектров возбуждения люминесценции свидетельствует об отсутствии внутримолекулярного переноса энергии электронного возбуждения с уровней лигандов $\left(\mathrm{NO}_{3}, \mathrm{HMPA}\right)$ на резонансные уровни люминесцентного центра.

\section{Список литературы}

[1] Bünzli J-C.G. // Chem. Rev. 2010. V. 110. P. 2729. doi 10.1021/cr900362e

[2] Bunzli J-C.G., Eliseeva S.V // Chem. Sci. 2013. V. 4. P. 1939. doi 10.1039/C3SC22126A

[3] Olawale D.O., Okoli O.O.I., Fontenot R.S., Hollerman W.A. (Eds.) Triboluminescence. Theory, Synthesis, and Application. Springer, Switzerland. 2016. Р. 39-63. [Электронный ресурс] Режим доступа: https:/www.springer.com/la/book/9783319388410

[4] Hao Z.M., Yang G.C., Song X.Z., Zhu M., Meng X., Zhao S.N., Song S.Y., Zhang H.J. // J. Mater. Chem. A. 2014. V. 2. P. 237. doi 10.1039/C3TA13179C

[5] Mirochnik A.G., Petrochenkova N.V., Shishov A.S., Bukvetskii B.V., Emelina T.B., Sergeev A.A., Voznesenskii S.S. /I Spectrochim. Acta. A. Mol. Biomol. Spectrosc. 2016. V. 155. P. 111. doi 10.1016/j.saa.2015.11.004

[6] Huang X.D., Xu Y., Fan K., Bao S.S., Kurmoo M., Zheng L.M. // Angew. Chem. 2018. V. 57. P. 8577. doi 10.1002/anie.201804102

[7] Venkataravanappa M., Basavaraj R.B., Darshan G.P., Prasad B.D.E., Sharma S.C., Prabha P.H., Nagabhushana H. // J. Rare Earths. 2018. V. 36. P. 690. doi 10.1016/j.jre.2017.11.013

[8] Dar W.A., Ahmed Z., Iftikhar K. // J. Photochem. Photobiolog. A. 2018. V. 356. P. 502. doi 10.1016/j.jphotochem.2017.12.017

[9] Wang J.H., Chorazy S., Nakabayashi K., Sieklucka B., Ohkoshi S. // J. Mater. Chem. C. 2018. V. 6. P. 473. doi $10.1039 / \mathrm{C} 7 \mathrm{TC} 03963 \mathrm{H}$

[10] Su Q., Pei Z., Chi L., Zhang H., Zhang Z., Zou F.J. // J. Alloys Compd. 1993. V. 192. P. 25. doi 10.1016/0925-8388(93)90174-L

[11] Liu X., Liu Y., Yan D., Zhu H., Liu C., Xu C., Liu Y., Wang $X$. // J. Mater. Chem. 2012. V. 22. P. 16839. doi 10.1039/C2JM32741D

[12] Hömmerich U., Nyein E., Freeman J.A., Amedzake P., Trivedi S.B., Zavada J.M.J. // J. Cryst. Growth. 2006. V. 287. P. 230. doi 10.1016/j.jcrysgro.2005.11.019

[13] Feng J., Zhou L., Song S.Y., Li Z.F., Fan W.Q., Sun L.N., Yu Y.N., Zhang H.J. // Dalton Trans. 2009. P. 6593. doi 10.1039/b906419b

[14] Wie K., Machewirth D.P., Wenzal J., Snitzer E., Sigel G.H. // Opt. Lett. 1994. V. 19. P. 904. doi 10.1364/OL.19.000904 
[15] Bïu S., Gopakumar N., Bunzli J-C.G., Scopelli R., Kim H.K., Reddy M.L.P. // Inorg. Chem. 2013. V. 52. P. 8750. doi 10.1021/ic400913f

[16] Bukvetskii B.V., Mirochnik A.G., Zhikhareva P.A. // J. Lumin. 2017. V. 32. P. $341-347$. doi 10.1002/bio.3184

[17] Буквецкий Б.В., Мирочник А.Г., Жихарева П.А., Карасев В.E. // Журн. структур. химии. 2010. № 6. C. 1200; Bukvetskii B.V., Mirochnik A.G., Zhikhareva P.A., Karasev V.E. // J. Struct. Chem. 2010. V. 51. N 6. P. 1164. doi 10.1007/s10947-010-0176-y

[18] Kharchenko V.I., Kurbatov I.A., Cherednichenko A.I., Mirochnik A.G., Zhikhareva P.A. // Spectrochim. Acta. A. Mol. Biomol. Spectrosc. 2017. V. 174. P. 297. doi 10.1016/j.saa.2016.12.004

[19] Bruker, SMART and SAINT-Plus. Versions 5.0. Data Collection and Processing Software for the SMART System. Madison, Wisconsin, USA: Bruker AXS Inc., 1998.

[20] Sheldrick G.M. SHELXTL/PC. Versions 5.10. An Integrated System for Solving, Refining and Displaying Crystal Structures from Diffraction Data, Madison, Wisconsin, USA: Bruker AXS Inc., 1998. 